\title{
Effects of Cyclopentolate on Form Deprivation Myopia in Guinea Pigs
}

\author{
Tao Li1, Xiaodong Zhou ${ }^{*}$, Zhi Chen ${ }^{2}$, Xingtao Zhou ${ }^{2}$ \\ ${ }^{1}$ Department of Ophthalmology, Jinshan Hospital of Fudan University, Shanghai, China \\ ${ }^{2}$ Department of Ophthalmology, Eye and ENT Hospital of Fudan University, Shanghai, China \\ Email: ${ }^{*}$ dzhou2013@126.com
}

Received 25 December 2014; accepted 6 February 2015; published 9 February 2015

Copyright (C) 2015 by authors and Scientific Research Publishing Inc.

This work is licensed under the Creative Commons Attribution International License (CC BY). http://creativecommons.org/licenses/by/4.0/

(c) (i) Open Access

\begin{abstract}
Purpose: To investigate the effects of intravitreal injection of cyclopentolate on form deprivation myopia in guinea pigs. Methods: Thirty-five guinea pigs at age of 3 weeks were randomly divided into 5 groups ( $n=7$ for each group): deprived, deprived plus saline, deprived plus cyclopentolate, normal control, and cyclopentolate group. Form deprivation was only performed in right eyes with translucent membranes for 4 weeks. Physiological saline and cyclopentolate were intravitreally injected into deprived eyes at four-day intervals. All the left eyes remained untreated as group control. Refraction was measured by retinoscopy after cycloplegia. The axial dimensions were measured by A-scan ultrasound. Subsequently, retinal histology was observed by light microscopy. Results: After 4 weeks of treatment, intravitreal injection of cyclopentolate significantly reduced the degree of myopia in the deprived eyes (from $-3.92 \mathrm{D}$ to $-0.86 \mathrm{D}, P<0.001$ ), and retarded the increase of vitreous chamber depth (from $3.83 \pm 0.06 \mathrm{~mm}$ to $3.70 \pm 0.05 \mathrm{~mm}, P<0.001$ ) and axial length (from $8.42 \pm 0.04 \mathrm{~mm}$ to $8.30 \pm 0.05 \mathrm{~mm}, P<0.001$ ) in the deprived eyes. Histological examination revealed no evidence of retinal damage of eyes injected with physiological saline or cyclopentolate compared with normal control eyes. Conclusions: Intravitreal administration of cyclopentolate reduces axial elongation of the deprived eyes in guinea pigs. Further investigations are required to identify the optimal dose.
\end{abstract}

\section{Keywords}

Cyclopentolate, Muscarinic Antagonist, Form Deprivation Myopia, Axial Length, Refraction

\section{Introduction}

Form deprivation myopia (FDM) in mammals has been linked to disruption of emmetropization due to poor

*Corresponding author. 
image quality on the retina of deprived eye. A variety of ocular conditions that lead to varying degrees of visual deprivation in human eyes such as corneal opacity [1] and vitreous haemorrhage [2] are associated with myopia in humans. It has been demonstrated in a wide range of animal species including chicks [3], tree shrews [4], guinea pigs [5] [6], monkeys [7] [8], fish [9] and mice [10]. The experimental myopia of animal models shares similar characteristic features with human myopia, such as an increase in the axial length of the eye [11].

Muscarinic antagonists were reported to inhibit or decrease the development of FDM [12]-[16]. McBrien et al. [12] found that the non-selective muscarinic antagonist atropine inhibited experimentally induced myopia through chronic intravitreal injection. Tropicamide, another non-selective muscarinic antagonist, was also proved to be partially effective in inhibiting myopia in chicks [16]. The M1-selective antagonist pirenzepine was effective in reducing the axial elongation associated with experimental myopia in a dose-dependent manner [13] [14]. Cottriall et al. [15] revealed that the M4-selective antagonist himbacine was effective in preventing the development of myopia in chicks. Many other antagonists were tested in the deprived eyes of chicks as well [16].

Atropine is also the most widely investigated pharmacological agent for the prevention of children myopia progression. The higher the concentration of atropine is, the greater the control effect of myopia progression is, and the more the adverse effects are [17] [18]. The safety profile of atropine (i.e., its effect on pupil size and accommodation) has always been of concern and prohibited many children from utilizing this medication. However, photophobia due to mydriasis and blurring of near vision from induced cycloplegia often disturb children and resulted in a high rate of noncompliance from children.

Cyclopentolate, a type of muscarinic antagonist, is widely used as a cycloplegic and mydriatic agent for eye examination in clinical practice. Yen and colleagues [19] found that the mean myopic progression of children with use of cyclopentolate $1 \%$ eye drops every night was statistically less than that with use of normal saline eye drops. Furthermore, topical administration of cyclopentolate dilated the pupil in all eyes of guinea pigs but did not change other ocular parameters (i.e., refraction, vitreous chamber depth, axial length) [20]. However, the long-term effect of cyclopentolate on myopia control is not fully determined, and it has not yet been evaluated the effectiveness on FDM in animals.

The guinea pigs are a promising alternative to other mammals for experimental myopia, as they are born with a well-developed visual system [5] [6]. The purpose of this study was to investigate the effects of intravitreal injection of cyclopentolate on FDM in guinea pigs.

\section{Materiors and Methods}

\subsection{Animals}

Thirty-five pigmented guinea pigs at age of 3 weeks were obtained from the breeding room in Thai town, Fengxian District, Shanghai City, China. These animals were randomly divided into 5 groups ( $n=7$ in each group): deprived, deprived plus saline, deprived plus cyclopentolate, normal control, and cyclopentolate group. Guinea pigs were reared at $25^{\circ} \mathrm{C}$ with a $12-12 \mathrm{~h}$ light-dark cycle. The animal research was approved by the Animal Care and Ethics Committee at Jinshan Hospital of Fudan University, Shanghai, China. The treatment and care of the animals were conducted according to the ARVO Statement for the Use of Animals in Ophthalmic and Vision research.

\subsection{Form Deprivation Myopia}

The procedure of form deprivation has been detailed in a previous study [5]. Briefly, the right eyes of guinea pigs were occluded with self-made translucent membranes, which were held in place based on their rubber-band effect around the mouth and head of guinea pigs. The left eye, nose, mouth and ears were exposed. The guinea pigs cooperated well in the process of wearing the occluders, and anaesthesia was not necessary for this procedure. The diffusers did not compromise the cornea, and the right eyes could blink behind the occluders freely. The occluders made from milky white latex gloves were opaque, soft and elastic with the thickness less than $0.06 \mathrm{~mm}$, and light transmission of $60 \%$. The diffusers were examined once a day to ensure they were in place.

\subsection{Treatment Protocols}

Guinea pigs were intraperitoneally injected with 100 mg/kg ketamine HCL (Gutian Pharmaceutical Company, 
Fujian, China). After anesthesia, the right eyes of the guinea pigs received intravitreal injections through the pars plana $1 \mathrm{~mm}$ from the limbus using a 26-gauge needle at four-day intervals for a total of 7 injections during 4week treatment periods according to their treatment group. The deprived plus cyclopentolate group and cyclopentolate group received $10 \mu \mathrm{L}$ of cyclopentolate $(10 \mu \mathrm{g} / \mu \mathrm{L}$; Alcon, US) at 9 a.m. To test for a possible vehicle effect, $10 \mu \mathrm{l}$ of physiological saline were intravitreally injected in the right eyes in deprived plus saline group. The occluders were renewed after every injection. All the left eyes remained untreated as a control.

\subsection{Refraction and Biometric Measurement}

Each eye was measured before treatment and after 4 weeks of treatment. Cycloplegia and dilation of the pupil was induced by 4 drops of tropicamide $0.5 \%$, and 30 minutes later ocular refraction was measured with a streak retinoscope. All refractive errors were measured in the horizontal and vertical meridians, which was described in Howlett et al. [6]. Refractions were reported as spherical equivalents (sphere plus half the cylinder). A refractive accuracy of $0.25 \mathrm{D}$ has been determined previously by Zhou et al. [21].

The axial dimensions were measured by A-scan ultrasound (11 MHz; Hiscan A/B, Opticon, Italy) under corneal topical anesthesia (oxybuprocaine hydrochloride $0.4 \%$, Santen, Japan), including axial length (a distance from the corneal apex to the vitreous-retinal interface, including cornea thickness), anterior chamber depth (a distance from the corneal apex to the front surface of the lens, including cornea thickness), lens thickness and vitreous chamber depth (a distance from the back of the crystalline lens to the vitreous-retinal interface). The ultrasound probe was directly in contact with the cornea during the axial measurement. A genuine measurement was confirmed when clear traces of various components of the eye with consistent waves and amplitudes were detected [22]. Peaks were selected for the front of the cornea, the front and back of the crystalline lens, and the vitreous-retinal interface. The average value was then used for analysis. All measurements were performed by the same examiner who was masked to the treatment group assignment.

\subsection{Retinal Histology}

Retinal tissue was acquired for retinal histology at the end of the treatment. Guinea pigs were administered a lethal dose of sodium pentobarbital $(150 \mathrm{mg} / \mathrm{kg}$ ). Right eyes of the animals were enucleated and fixed with paraformaldehyde $4 \%$ in $0.1 \mathrm{M}$ phosphate buffer solution (PBS, $\mathrm{pH} 7.4$ ) for $24 \mathrm{~h}$ at $4^{\circ} \mathrm{C}$. The eyeballs were then hemisected equatorially with removal of the lens and vitreous body. The eyecups were immersed in fresh paraformaldehyde $4 \%$ solution, followed by a routine histological processing text. Sections of approximately $4-\mu m$ thickness ( $0.5 \mathrm{~mm}$ from the temporal margin of the optic disc) were cut on a microtome, mounted on slides, stained with hematoxylin and eosin. Slides were examined at $\times 200$ magnification on an Olympus microscope fitted with a digital camera.

\subsection{Statistical Analysis}

Statistical Package for the Social Sciences software (version 16.0, SPSS, Inc.) was used for statistical analysis. Data were expressed as mean \pm standard deviation (SD). Paired t tests were performed to compare intra-group differences. One-way analysis of variance (ANOVA) was used to compare inter-group differences. If ANOVA showed a significant difference, a Bonferroni post-hoc test was applied to determine whether there were significant differences between pairs of groups. $P<0.05$ was considered statistically significant.

\section{Results}

\subsection{Effect of Cyclopentolate on Refraction}

The eyes of guinea pigs, at age of 3 weeks, initially showed mild hyperopia. No statistically significant difference in the refraction was observed between the right and left eyes. After the right eyes were occluded for 4 weeks, the deprived eyes became significantly myopic compared with the fellow eyes and normal control eyes $(P<0.001$ and $P<0.001$, respectively; Table 1 and Figure 1$)$.

Intravitreal injection of cyclopentolate $(700 \mu \mathrm{g})$ significantly reduced the degree of myopia in the deprived eyes compared to deprived plus saline group (from $-3.92 \pm 0.64 \mathrm{D}$ to $-0.86 \pm 0.69 \mathrm{D}, P<0.001$; Table 1 ). However, FDM could still be induced in deprived eyes which had undergone cyclopentolate treatment, because 
Table 1. Cycloplegic ocular refraction and biometric dimensions of the right and left eyes in guinea pigs at the end of 4-week treatment period.

\begin{tabular}{ccccccc}
\hline Groups & Eye & Refraction (D) & Axial length $(\mathrm{mm})$ & $\begin{array}{c}\text { Anterior chamber } \\
\text { depth }(\mathrm{mm})\end{array}$ & $\begin{array}{c}\text { Lens thickness } \\
(\mathrm{mm})\end{array}$ & $\begin{array}{c}\text { Vireous chamber } \\
\text { depth }(\mathrm{mm})\end{array}$ \\
\hline \multirow{2}{*}{ Deprived } & Right & $-3.86 \pm 0.65^{\mathrm{c}}$ & $8.41 \pm 0.06^{\mathrm{c}}$ & $1.21 \pm 0.04$ & $3.39 \pm 0.04$ & $3.81 \pm 0.05^{\mathrm{c}}$ \\
& Left & $1.29 \pm 0.31$ & $8.24 \pm 0.04$ & $1.22 \pm 0.03$ & $3.39 \pm 0.03$ & $3.63 \pm 0.04$ \\
Deprived + saline & Right & $-3.92 \pm 0.64^{\mathrm{c}}$ & $8.42 \pm 0.04^{\mathrm{c}}$ & $1.21 \pm 0.04$ & $3.38 \pm 0.04$ & $3.83 \pm 0.06^{\mathrm{c}}$ \\
& Left & $1.18 \pm 0.27$ & $8.23 \pm 0.03$ & $1.21 \pm 0.04$ & $3.38 \pm 0.04$ & $3.64 \pm 0.04$ \\
Deprived + & Right & $-0.86 \pm 0.69^{\mathrm{abc}}$ & $8.30 \pm 0.05^{\mathrm{abc}}$ & $1.21 \pm 0.05$ & $3.39 \pm 0.04$ & $3.70 \pm 0.05^{\mathrm{abc}}$ \\
cyclopentolate & Left & $1.26 \pm 0.28$ & $8.23 \pm 0.03$ & $1.21 \pm 0.04$ & $3.38 \pm 0.03$ & $3.64 \pm 0.04$ \\
Normal control & Right & $1.27 \pm 0.28$ & $8.22 \pm 0.04$ & $1.21 \pm 0.04$ & $3.39 \pm 0.04$ & $3.62 \pm 0.04$ \\
& Left & $1.23 \pm 0.27$ & $8.22 \pm 0.05$ & $1.21 \pm 0.03$ & $3.38 \pm 0.03$ & $3.63 \pm 0.05$ \\
Cyclopentolate & Right & $1.26 \pm 0.30$ & $8.23 \pm 0.04$ & $1.20 \pm 0.03$ & $3.39 \pm 0.03$ & $3.64 \pm 0.04$ \\
\hline
\end{tabular}

Data were expressed in mean \pm SD. ${ }^{\text {a } P}<0.05$, compared with deprived group; ${ }^{\mathrm{b}} P<0.05$, compared with deprived plus saline group; ${ }^{\mathrm{c}} \mathrm{P}<0.05$, compared with normal control group.

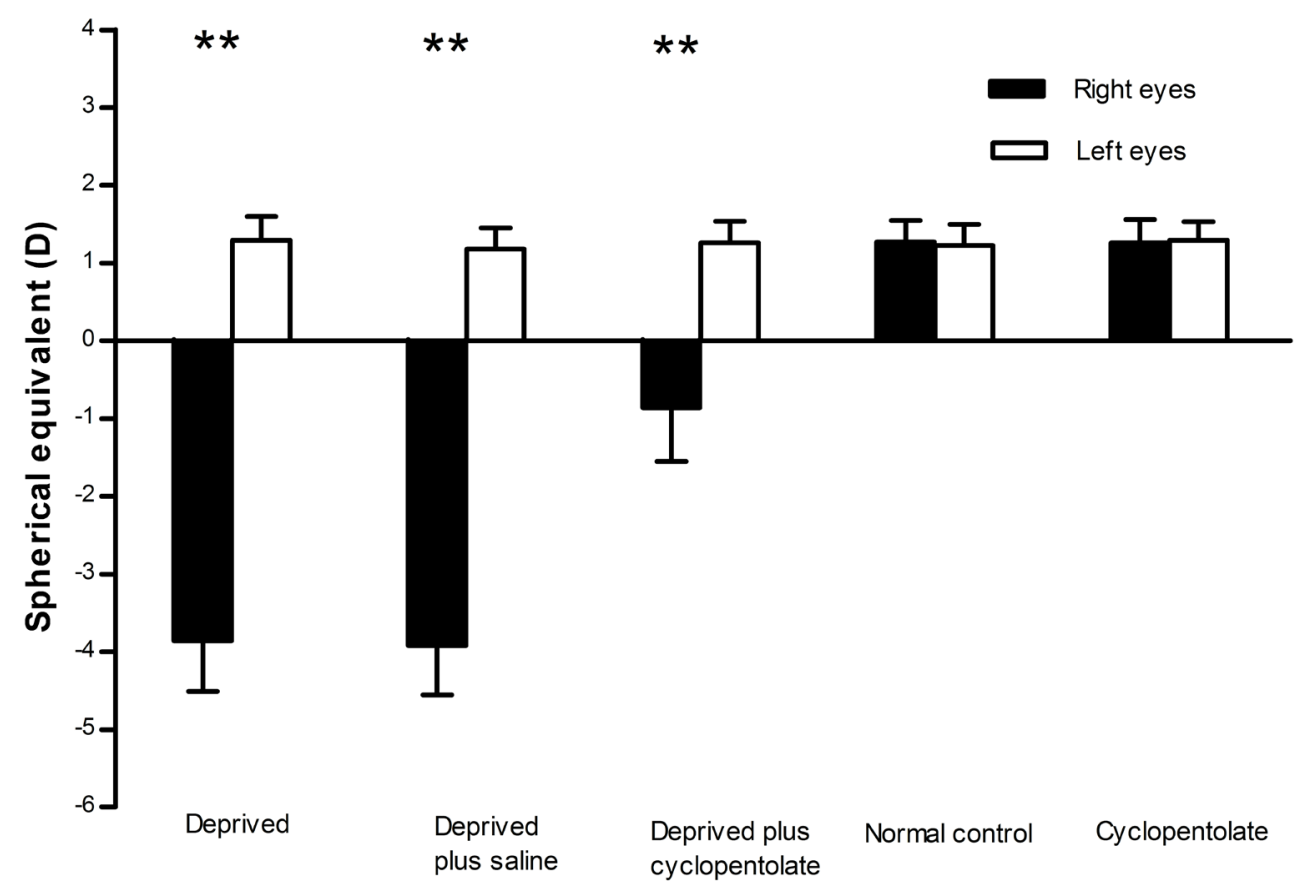

Figure 1. Average refraction (mean $\pm \mathrm{SD}$ ) of the right and left eyes at the end of 4-week treatment period in the different groups ( $n=7$ guinea pigs for each group). Asterisks refer to the difference between the right and left eyes in each group. ${ }^{* *} P<0.001 ;{ }^{*} P<0.05$.

its refraction showed a statistically significant difference compared with fellow eyes $(P<0.001)$. In contrast, intravitreal injection of physiological saline caused no significant effect on the refraction of deprived eyes compared to the deprived eyes in the deprived group $(P=1.00)$. In non-deprived age-matched animals, there was no statistically significant difference in the ocular refraction of between cyclopentolate treatment and normal control. No statistically significant difference was observed in the refraction of fellow eyes in the different treatment groups $(\mathrm{F}=0.475, P=0.75)$. 


\subsection{Effects of Cyclopentolate on Ocular Biometric Dimensions}

After 4 weeks of treatment, there were significant differences in vitreous chamber depth (VCD) and axial length (AL) between the deprived and fellow eyes in deprived plus cyclopentolate group $(P<0.001$ and $P<0.001$, respectively; Figure 2, Figure 3). Significant differences in VCD and AL were also observed between the deprived eyes in deprived plus cyclopentolate group and the deprived eyes in deprived plus saline group $(P<$ 0.001 and $P<0.001$, respectively; Table 1 ). Intravitreal injection of cyclopentolate (700 $\mu$ g) significantly retarded the increase of VCD (from $3.83 \pm 0.06 \mathrm{~mm}$ to $3.70 \pm 0.05 \mathrm{~mm}, P<0.001$; Table 1) and AL (from $8.42 \pm$ $0.04 \mathrm{~mm}$ to $8.30 \pm 0.05 \mathrm{~mm}, P<0.001$; Table 1 ) in the deprived eyes compared to those of the deprived eyes in the deprived group and deprived plus saline group.

However, the increase of VCD and AL in the deprived eyes was not suppressed completely by cyclopentolate treatment, because its VCD and AL showed a statistically significant difference compared with fellow eyes. In contrast, intravitreal injection of physiological saline caused no significant effect on VCD and AL of deprived eyes compared to the deprived group. In non-deprived age-matched animals, there was no statistically significant difference in the VCD and AL of between cyclopentolate treatment and normal control.

As illustrated in Table 1, there were no statistically significant differences in anterior chamber depth, lens thickness, VCD, and AL between the right and left eyes in normal control group. There were no statistically significant differences in anterior chamber depth and lens thickness of deprived eyes in different treatment groups, as well as anterior chamber depth, lens thickness, VCD and AL of fellow eyes in different treatment groups.

\subsection{Retinal Histology}

As can be seen in Figure 4, guinea pigs showed a normal arrangement of ganglion cell layer (GCL), inner plexiform layer (IPL), inner nuclear layer (INL), outer plexiform layer (OPL), outer nuclear layer (ONL) and photoreceptor layer (PL). Histological examination revealed these layers were similar in retinal structure and integrity among all the 5 groups. There was no apparent evidence of retinal damage of eyes injected with physiological saline or cyclopentolate compared with normal control eyes.

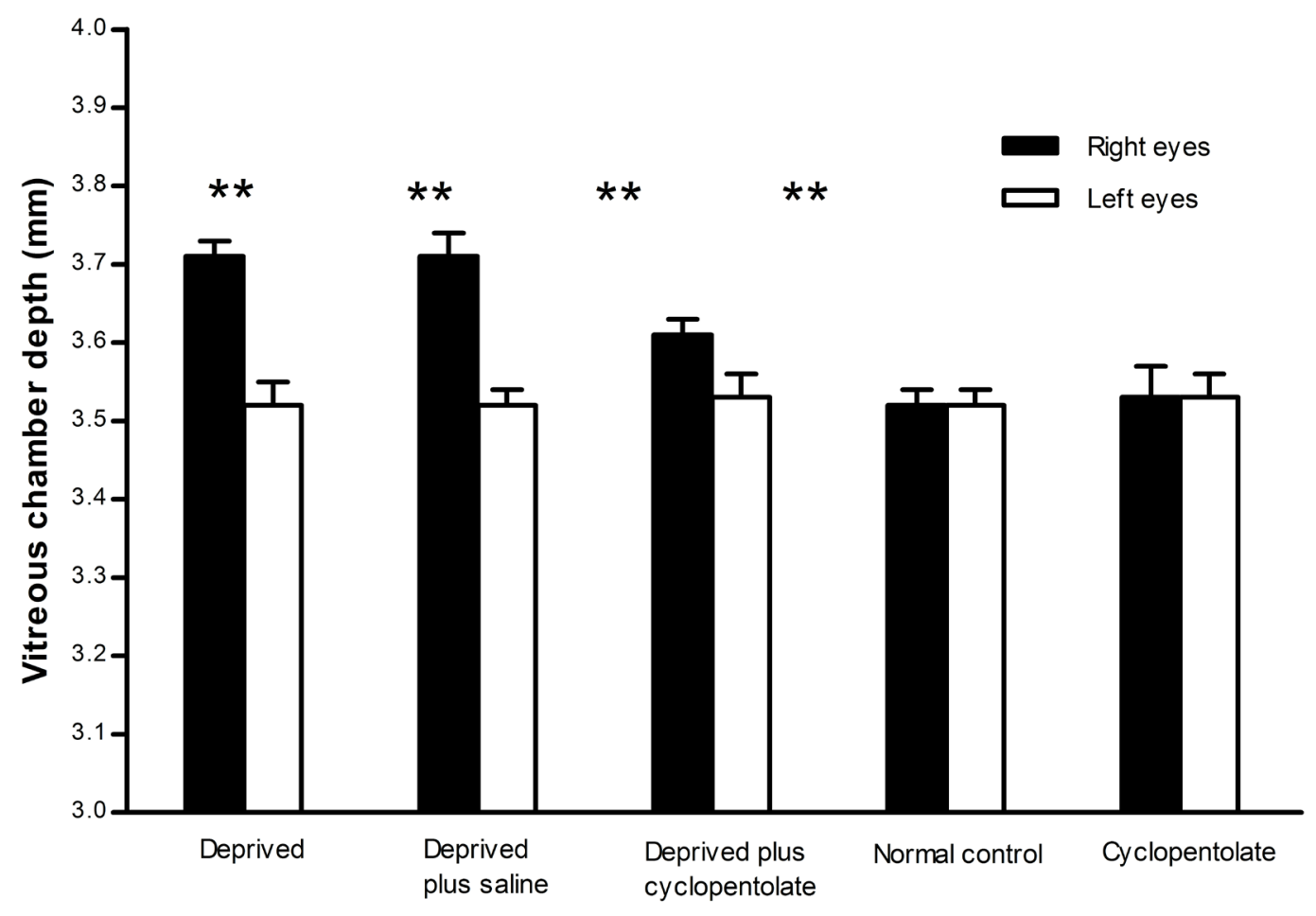

Figure 2. Average vitreous chamber depth (mean $\pm \mathrm{SD}$ ) of the right and left eyes at the end of 4-week treatment period in the different groups ( $n=7$ guinea pigs for each group). Asterisks refer to the difference between the right and left eyes in each group. ${ }^{* *} P<0.001 ;{ }^{*} P<0.05$. 


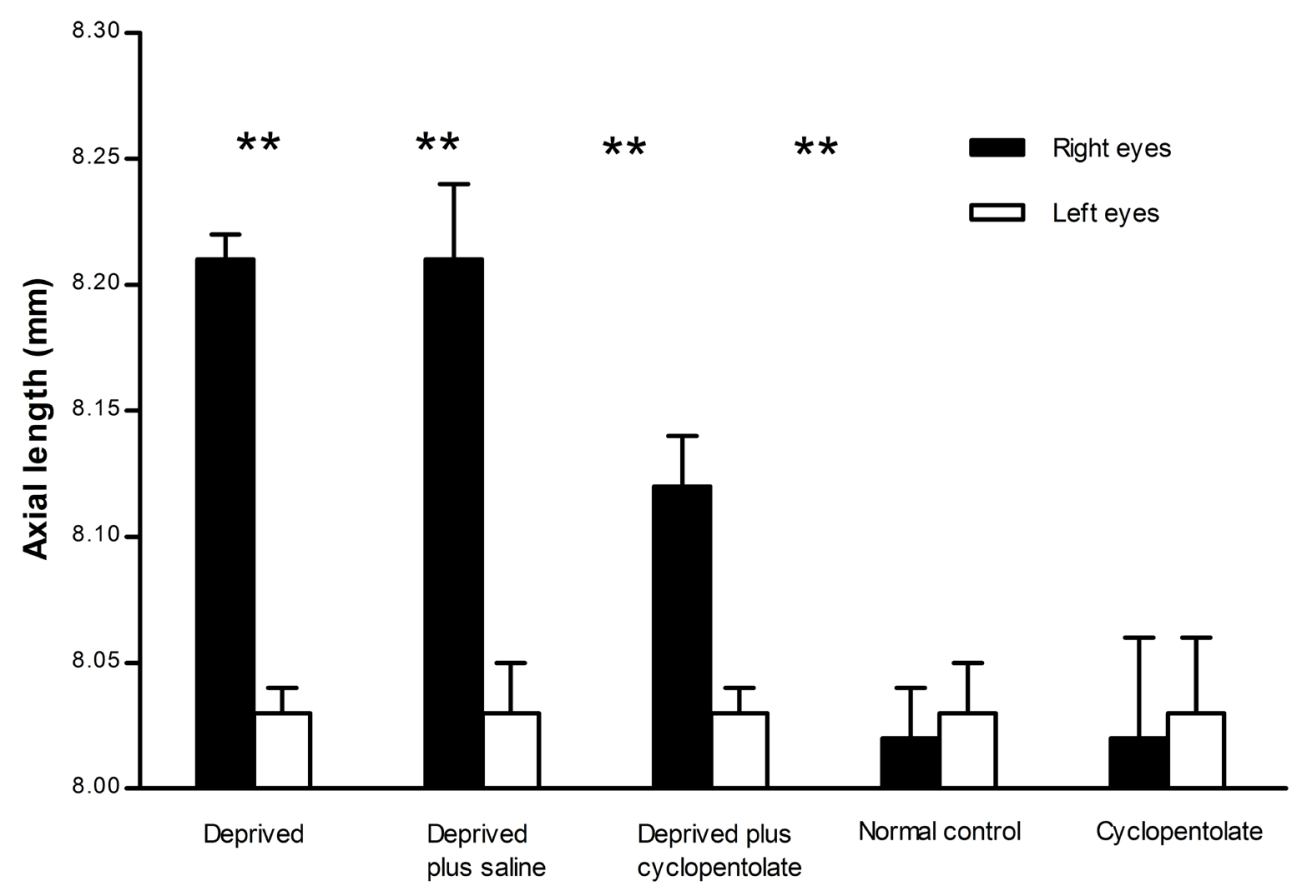

Figure 3. Average axial length (mean \pm SD) of the right and left eyes at the end of 4-week treatment period in the different groups ( $\mathrm{n}=7$ guinea pigs for each group). Asterisks refer to the difference between the right and left eyes in each group. ${ }^{* *} P<0.001 ;{ }^{*} P<0.05$.

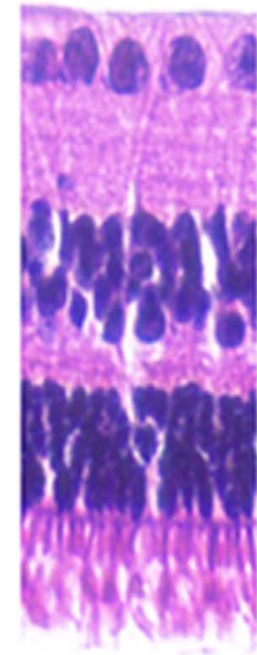

A

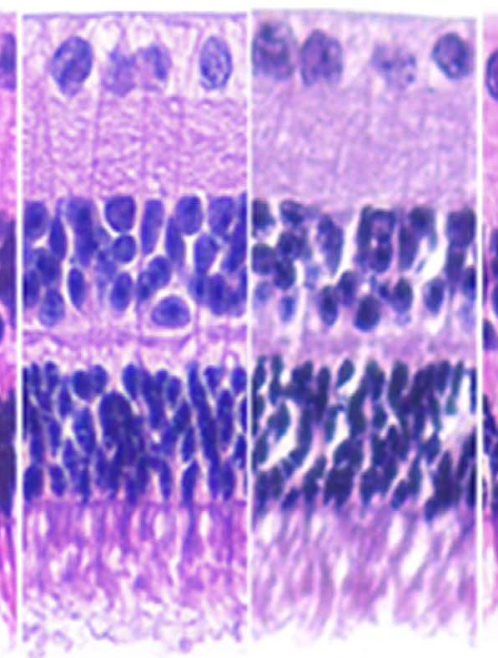

B
C

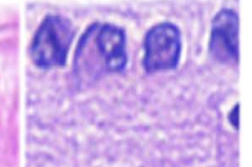

GCL

IPL

INL

OPL

ONL

PL

Figure 4. Light microscopy in right eyes of guinea pigs for the six groups. No abnormality was detected in any layers of the retinal tissue from posterior pole ( $0.5 \mathrm{~mm}$ away from optic disc). GCL: ganglion cell layer; IPL: inner plexiform layer; INL: inner nuclear layer; OPL: outer plexiform layer; ONL: outer nuclear layer; PL: photoreceptor layer; A: deprived group; B: deprived plus saline group; C: deprived plus cyclopentolate group; D: normal control group; E: cyclopentolate group; Bar: $50 \mu \mathrm{m}$.

\section{Discussion}

The present study demonstrated intravitreal administration of cyclopentolate could reduce the excessive axial elongation and the concomitant development of FDM in guinea pigs. Furthermore, our findings of similar results for anterior chamber depth and lens thickness across all the groups indicate that their development was unrelated to the different treatment modalites. 
Cyclopentolate is a muscarinic receptor antagonist like atropine [23], which is widely used in clinical practice. Atropine has many ocular and systemic side effects (e.g., allergic conjunctivitis, glare, gastric pain) [18] compared to cyclopentolate, and hence it is not a popular choice of drug for myopia treatment. Although short-acting, minimal side effects of cyclopentolate make it a potential drug for anti-myopia therapy. Observing 96 children in Taiwan, Yen et al. [19] found that the mean myopic progression was $-0.578 \mathrm{D} / \mathrm{y}$ in the cyclopentolate group and $-0.219 \mathrm{D} / \mathrm{y}$ in the atropine group, both of which were statistically less than that in the control group. However, no further study reported the effect of cyclopentolate on myopia in children and animal models. To the best of our knowledge, this study is the first to evaluate the effectiveness of intravitreal injection of cyclopentolate on FDM in guinea pig eyes. In the current study, intravitreal injection of cyclopentolate showed a significant inhibitory effect on deprivation-induced myopia in guinea pigs, but there were still significant differences in refraction, VCD and AL between the deprived and fellow eyes. They could not completely inhibit the development of FDM, suggesting the doses of cyclopentolate $(700 \mu \mathrm{g})$ or the frequency of its administration (intravitreal injections at four-day intervals) might be too low to induce a complete elimination of myopia. In addition, after intravitreal injection of cyclopentolate in the non-deprived animals, their refraction and ocular biometric dimensions showed no significant changes, indicating that local cyclopentolate had no effect on the normal refractive development in guinea pigs.

Topical administration of pirenzepine can prevent induced form-deprivation [24] and lens-induced [25] experimental myopia in guinea pigs by inhibiting axial elongation. Evaluating various concentrations of the muscarinic antagonists, Luft et al. [16] found that only atropine, pirenzepine, and oxyphenonium prevented FDM, whereas others including tropicamide, dexetimide, scopolamine, benztropine, dicyclomine, gallamine, mepenzolate, propantheline, procyclidine, 4-diphenylacetoxy- $N$-methylpiperidine, hexahydro-sila-difenidol, p-fluorohexahydro-sila-difenidol, methoctramine, AFDX-116, quinuclidinyl benzilate, were ineffective or partially effective. The action of cyclopentolate in the present study may be different from previous antagonists due to different types of antagonists or experimental species.

The deprived eyes whether injected or not showed a decrease in mean refraction, accompanied by an elongation of the VCD and AL. Previous studies revealed an increase in AL of the deprived eye was mainly due to elongation of the vitreous chamber [6] [26]. Compared with only deprivation, physiological saline injection had little effect on refraction and ocular biometric dimensions. Although the saline vehicle injection may disturb the intraocular balance [27], it had no significant influence on the natural development of eyes.

Histological evidence from the present study found no retinal damage at the effective dose of $700 \mu \mathrm{g}$ cyclopentolate. Retinal structure and integrity in guinea pigs induced by intravitreal injection of cyclopentolate was consistent with the results of intravitreal administration of atropine, pirenzipine and tropicamide in chicks [16]. Le et al. [24] also found no obviously toxic effects on the eyes treated with topical administration of pirenzepine.

Muscarinic receptors are one of the important facts during the development of myopia. Although the ocular tissues of guinea pigs express muscarinic subtypes M1 to M5 [28], it remains unknown how the muscarinic antagonists affect ocular growth. The effect of atropine on myopia control is considered by a retinal based mechanism mediated via muscarinic receptor signaling and non-accommodative way [28]. Cyclopentolate is a nonspecific antagonist, and hence its interaction with different receptors is potentially complex. The mechanism for cyclopentolate treatment may be through molecular signals involved the local connection between the retina and sclera, which directly influence the sclera growth [29] or induce a series of signaling cascade from retinal pigment epithelial to sclera [30]. We don't know whether anti-myopia effects of cyclopentolate is also independent of accommodation (such as with atropine). In addition, further investigations are needed to confirm whether effects of cyclopentolate could be mediated by nonmuscarinic mechanism. It is well-known that muscarinic antagonist benztropine blocks dopamine transporter [31], thus cyclopentolate may also exert some similar activity through dopamine system.

\section{Conclusion}

In conclusion, intravitreal injections of cyclopentolate are effectively able to reduce the refraction, VCD and AL of deprived eyes in guinea pigs. Further investigations are required to identify the optimal dose of cyclopentolate treatment. 


\section{Conflict of Interests}

The authors have no financial or proprietary interest in the subject matter of this paper.

\section{Acknowledgements}

This work was supported by Grant from Shanghai Municipality Health Bureau Youth Project (2013-121) and Grant from Shanghai Municipality Jinshan District Health Bureau Youth Project (JSKJ-KTQN-2013-02).

\section{References}

[1] Gee, S.S. and Tabbara, K.F. (1988) Increase in Ocular AXIAL Length in Patients with Corneal Opacification. Ophthalmology, 95, 1276-1278. http://dx.doi.org/10.1016/S0161-6420(88)33035-6

[2] Miller-Meeks, M.J., Bennett, S.R., Keech, R.V. and Blodi, C.F. (1990) Myopia Induced by Vitreous Hemorrhage. American Journal of Ophthalmology, 109, 199-203. http://dx.doi.org/10.1016/S0002-9394(14)75987-2

[3] Wallman, J., Turkel, J. and Trachtman, J. (1978) Extreme Myopia Produced by Modest Change in Early Visual experience. Science, 201, 1249-1251. http://dx.doi.org/10.1126/science.694514

[4] Siegwart, J.J. and Norton, T.T. (1998) The Susceptible Period for Deprivation-Induced Myopia in Tree Shrew. Vision Research, 38, 3505-3515. http://dx.doi.org/10.1016/S0042-6989(98)00053-4

[5] Lu, F., Zhou, X., Zhao, H., Wang, R., Jia, D., Jiang, L., et al. (2006) Axial Myopia Induced by a Monocularly-Deprived Facemask in Guinea Pigs: A Non-Invasive and Effective Model. Experimental Eye Research, 82, 628-636. http://dx.doi.org/10.1016/j.exer.2005.09.001

[6] Howlett, M.H. and McFadden, S.A. (2006) Form-Deprivation Myopia in the Guinea Pig (Cavia porcellus). Vision Research, 46, 267-283. http://dx.doi.org/10.1016/j.visres.2005.06.036

[7] Smith, E.R., Huang, J., Hung, L.F., Blasdel, T.L., Humbird, T.L. and Bockhorst, K.H. (2009) Hemiretinal form Deprivation: Evidence for Local Control of Eye Growth and Refractive Development in Infant Monkeys. Investigative Ophthalmology \& Visual Science, 50, 5057-5069. http://dx.doi.org/10.1167/iovs.08-3232

[8] Huang, J., Hung, L.F., Ramamirtham, R., Blasdel, T.L., Humbird, T.L., Bockhorst, K.H., et al. (2009) Effects of Form Deprivation on Peripheral Refractions and Ocular Shape in Infant Rhesus Monkeys (Macaca mulatta). Investigative Ophthalmology \& Visual Science, 50, 4033-4044. http://dx.doi.org/10.1167/iovs.08-3162

[9] Shen, W., Vijayan, M. and Sivak, J.G. (2005) Inducing Form-Deprivation Myopia in fish. Investigative Ophthalmology \& Visual Science, 46, 1797-1803. http://dx.doi.org/10.1167/iovs.04-1318

[10] Tejedor, J. and de la Villa, P. (2003) Refractive Changes Induced by Form Deprivation in the Mouse Eye. Investigative Ophthalmology \& Visual Science, 44, 32-36. http://dx.doi.org/10.1167/iovs.01-1171

[11] Meng, W., Butterworth, J., Malecaze, F. and Calvas, P. (2011) Axial Length of Myopia: A Review of Current Research. Ophthalmologica, 225, 127-134. http://dx.doi.org/10.1159/000317072

[12] McBrien, N.A., Moghaddam, H.O. and Reeder, A.P. (1993) Atropine Reduces Experimental Myopia and Eye Enlargement via a Nonaccommodative Mechanism. Investigative Ophthalmology \& Visual Science, 34, 205-215.

[13] Leech, E.M., Cottriall, C.L. and McBrien, N.A. (1995) Pirenzepine Prevents form Deprivation Myopia in a Dose Dependent Manner. Ophthalmic and Physiological Optics, 15, 351-356. http://dx.doi.org/10.1016/0275-5408(95)00074-N

[14] Cottriall, C.L., McBrien, N.A., Annies, R. and Leech, E.M. (1999) Prevention of Form-Deprivation Myopia with Pirenzepine: A Study of Drug Delivery and Distribution. Ophthalmic and Physiological Optics, 19, 327-335. http://dx.doi.org/10.1016/S0275-5408(98)00079-9

[15] Cottriall, C.L., Truong, H.T. and McBrien, N.A. (2001) Inhibition of Myopia Development in Chicks Using Himbacine: A Role for M4 Receptors? Neuroreport, 12, 2453-2456. http://dx.doi.org/10.1097/00001756-200108080-00033

[16] Luft, W.A., Ming, Y. and Stell, W.K. (2003) Variable Effects of Previously Untested Muscarinic Receptor Antagonists on Experimental Myopia. Investigative Ophthalmology \& Visual Science, 44, 1330-1338. http://dx.doi.org/10.1167/iovs.02-0796

[17] Chua, W.H., Balakrishnan, V., Chan, Y.H., Tong, L., Ling, Y., Quah, B.L., et al. (2006) Atropine for the Treatment of Childhood Myopia. Ophthalmology, 113, 2285-2291. http://dx.doi.org/10.1016/j.ophtha.2006.05.062

[18] Chia, A., Chua, W.H., Cheung, Y.B., Wong, W.L., Lingham, A., Fong, A., et al. (2012) Atropine for the Treatment of Childhood Myopia: Safety and Efficacy of $0.5 \%, 0.1 \%$, and $0.01 \%$ Doses (Atropine for the Treatment of Myopia 2). Ophthalmology, 119, 347-354. http://dx.doi.org/10.1016/j.ophtha.2011.07.031

[19] Yen, M.Y., Liu, J.H., Kao, S.C. and Shiao, C.H. (1989) Comparison of the Effect of Atropine and Cyclopentolate on Myopia. Annals of Ophthalmology, 21, 180-182, 187. 
[20] Fang, F., Huang, F., Xie, R., Li, C., Liu, Y., Zhu, Y., et al. (2015) Effects of Muscarinic Receptor Modulators on Ocular Biometry of Guinea Pigs. Ophthalmic and Physiological Optics, 35, 60-69. http://dx.doi.org/10.1111/opo.12166

[21] Zhou, X., Lu, F., Xie, R., Jiang, L., Wen, J., Li, Y., et al. (2007) Recovery from Axial Myopia Induced by a Monocularly Deprived Facemask in Adolescent (7-Week-Old) Guinea Pigs. Vision Research, 47, 1103-1111. http://dx.doi.org/10.1016/j.visres.2007.01.002

[22] Zhou, X., Qu, J., Xie, R., Wang, R., Jiang, L., Zhao, H., et al. (2006) Normal Development of Refractive State and Ocular Dimensions in Guinea Pigs. Vision Research, 46, 2815-2823. http://dx.doi.org/10.1016/j.visres.2006.01.027

[23] Palamar, M., Egrilmez, S., Uretmen, O., Yagci, A. and Kose, S. (2011) Influences of Cyclopentolate Hydrochloride on Anterior Segment Parameters with Pentacam in Children. Acta Ophthalmologica, 89, e461-e465. http://dx.doi.org/10.1111/j.1755-3768.2011.02122.x

[24] Le, Q.H., Cheng, N.N., Wu, W. and Chu, R.Y. (2005) Effect of Pirenzepine Ophthalmic Solution on Form-Deprivation Myopia in the Guinea Pigs. Chinese Medical Journal, 118, 561-566.

[25] Ouyang, C.H., Chu, R.Y. and Hu, W.Z. (2003) Effects of Pirenzepine on Lens-Induced Myopia in the Guinea-Pig. Chinese Journal of Ophthalmology, 39, 348-351.

[26] Mutti, D.O., Mitchell, G.L., Sinnott, L.T., Jones-Jordan, L.A., Moeschberger, M.L., Cotter, S.A., et al. (2012) Corneal and Crystalline Lens Dimensions before and after Myopia Onset. Optometry and Vision Science, 89, 251-262.

[27] Gao, Q., Liu, Q., Ma, P., Zhong, X., Wu, J. and Ge, J. (2006) Effects of Direct Intravitreal Dopamine Injections on the Development of Lid-Suture Induced Myopia in Rabbits. Graefe's Archive for Clinical and Experimental Ophthalmology, 244, 1329-1335. http://dx.doi.org/10.1007/s00417-006-0254-1

[28] McBrien, N.A., Stell, W.K. and Carr, B. (2013) How Does Atropine Exert Its Anti-Myopia Effects? Ophthalmic and Physiological Optics, 33, 373-378. http://dx.doi.org/10.1111/opo.12052

[29] Liu, Q., Wu, J., Wang, X. and Zeng, J. (2007) Changes in Muscarinic Acetylcholine Receptor Expression in Form Deprivation Myopia in Guinea Pigs. Molecular Vision, 13, 1234-1244.

[30] Bitzer, M., Kovacs, B., Feldkaemper, M. and Schaeffel, F. (2006) Effects of Muscarinic Antagonists on ZENK Expression in the Chicken Retina. Experimental Eye Research, 82, 379-388. http://dx.doi.org/10.1016/j.exer.2005.07.010

[31] Coyle, J.T. and Snyder, S.H. (1969) Antiparkinsonian Drugs: Inhibition of Dopamine Uptake in the Corpus Striatum as a Possible Mechanism of Action. Science, 166, 899-901. http://dx.doi.org/10.1126/science.166.3907.899 
Scientific Research Publishing (SCIRP) is one of the largest Open Access journal publishers. It is currently publishing more than 200 open access, online, peer-reviewed journals covering a wide range of academic disciplines. SCIRP serves the worldwide academic communities and contributes to the progress and application of science with its publication.

Other selected journals from SCIRP are listed as below. Submit your manuscript to us via either submit@scirp.org or Online Submission Portal.
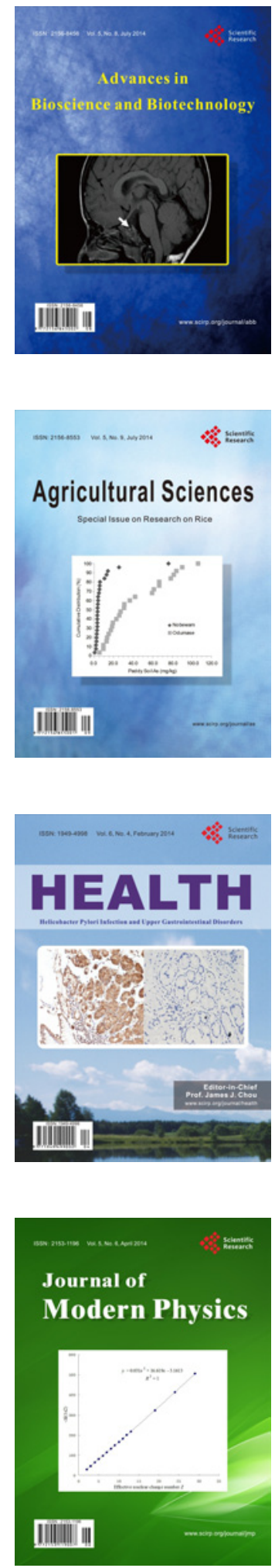
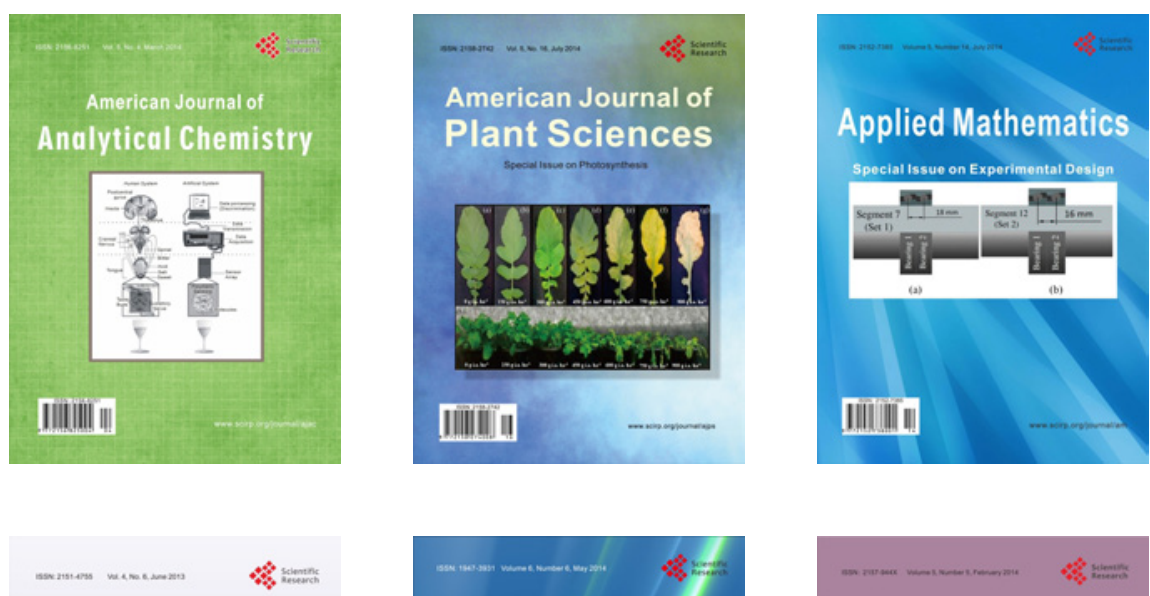

Creative Education
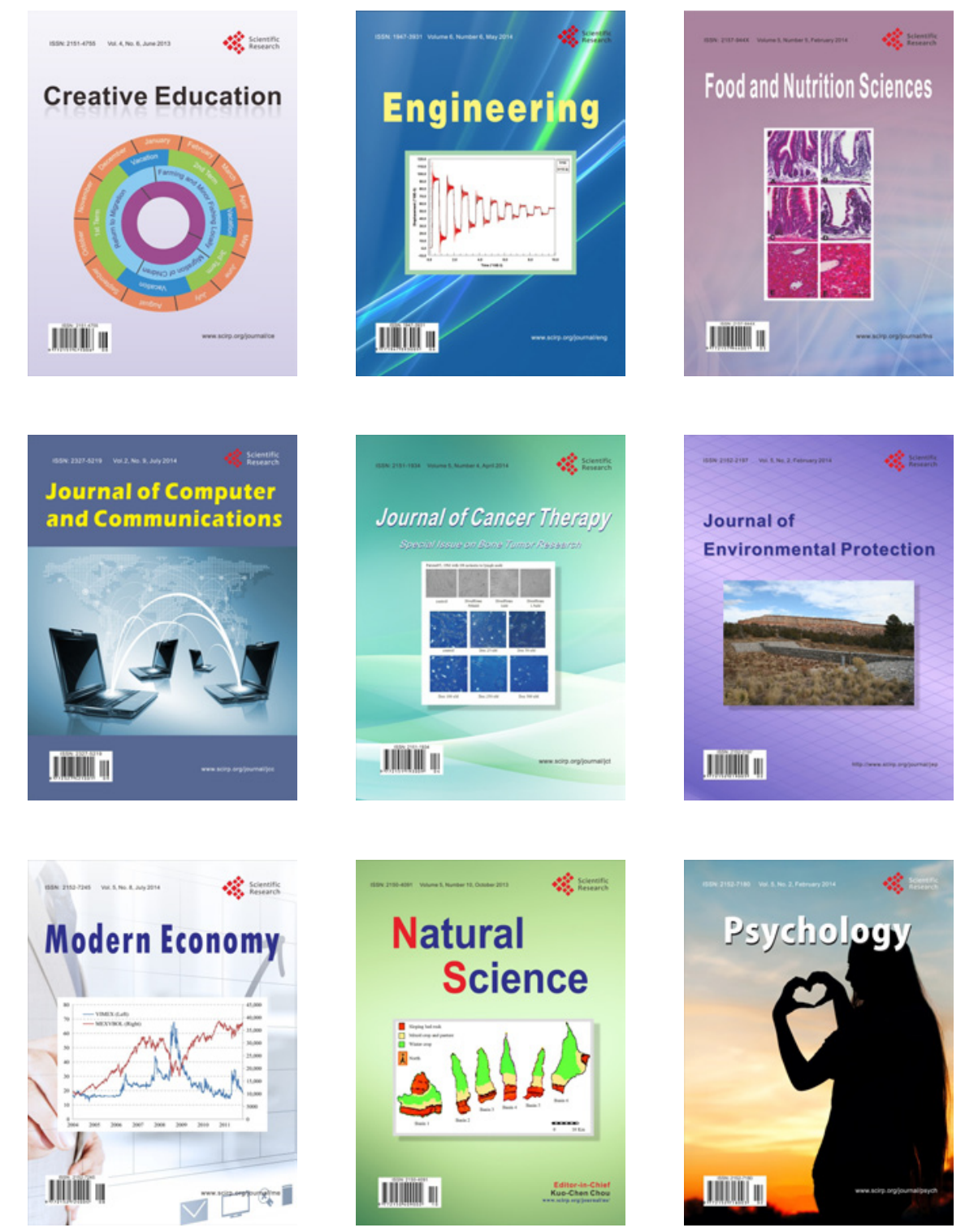